\title{
Anti-bullying procedures for schools in Ireland: principals' responses and perceptions
}

\section{Mairéad Foody, Helena Murphy, Paul Downes \& James O’Higgins Norman}

To cite this article: Mairéad Foody, Helena Murphy, Paul Downes \& James O'Higgins Norman (2018) Anti-bullying procedures for schools in Ireland: principals' responses and perceptions, Pastoral Care in Education, 36:2, 126-140, DOI: 10.1080/02643944.2018.1453859

To link to this article: https://doi.org/10.1080/02643944.2018.1453859

\section{Published online: 27 Mar 2018}

Submit your article to this journal $匚$

山 Article views: 668

Q View related articles

View Crossmark data 


\title{
Anti-bullying procedures for schools in Ireland: principals' responses and perceptions
}

\author{
Mairéad Foody, Helena Murphy, Paul Downes and James O’Higgins Norman \\ Anti-bullying Research and Resource Centre, Dublin City University, St Patrick's Campus, Dublin, \\ Republic of Ireland
}

\begin{abstract}
The role of the principal is imperative in creating a school climate that nurtures differences and equality at the same time. Policy and legislation in Ireland dictates the responsibility of school principals in preventing and intervening in issues relating to bullying. The current research investigates the extent to which principals consider the impact of bullying on their students and the strategies they take to combat it in their schools. We consider how principals respond to bullying and what supports they feel are missing for them to adhere to relevant policy. A sample of 918 principals from a range of schools across Ireland completed an online survey. The results demonstrated some positive actions by principals such as the provision of anti-bullying policies. However, they also document areas that need more action such as increased access to counsellors and appointing a specific staff member to deal with and tackle bullying in each school. Guidance from the Department of Education and Skills in Ireland on the development and provision of an anti-bullying programme is called for. Results are discussed in light of the current Anti-Bullying Procedures established by the Department of Education and Skills and the Action Plan for Bullying 2013.
\end{abstract}

\section{ARTICLE HISTORY}

Received 27 November 2017

Accepted 26 January 2018

\section{KEY WORDS}

Bullying; principals; schools; policy; Ireland

\section{Introduction}

Despite decades of research, exposure to bullying is still a threat for our children and adolescents, especially in school settings (Kasen, Berenson, Cohen, \& Johnson, 2004). Research tells us that individuals involved in bullying in any capacity (i.e. as a bully, victim or both) are at increased risk to develop mental health and/or disciplinary problems that could continue into adulthood (e.g. Ttofi, Farrington, \& Lösel, 2012; Wolke, Copeland, Angold, \& Costello, 2013; Wolke, Schreier, Zanarini, $\&$ Winsper, 2012). In addition, the experience can negatively affect those who witness bullying incidents but are not directly involved (Rivers, Poteat, Noret, Ashurst, \& Kamphaus, 2009). This presents a serious picture of the reality of bullying and 
highlights the prevention of bullying as a public health issue (Srabstein \& Leventhal, 2010; United Nations, 2013).

While bullying can happen almost anywhere, the most widely studied setting is in school. It is therefore not surprising that the responsibility for dealing with bullying has generally been placed on principals and educational staff. As such, many international governments have produced legislation and recommendations outlining the role of schools in bullying prevention and interventions. In Ireland, school principals have been given a clear mandate to address bullying through the Anti-Bullying Procedures for Primary and Post-Primary Schools (2013) which established mandatory procedures (e.g. the inclusion of an anti-bullying policy) when dealing with bullying incidents.

\section{School bullying in Ireland}

Schools in the Republic of Ireland can be broadly categorised into two groups respective of age. Children start primary school at the age of $4 / 5$ years and continue until $6^{\text {th }}$ class (12/13 years). The post-primary years refer to the period after primary school until the age of $17 / 18$ when students can finish at the highest stage of post-primary education, which is the Leaving Certificate examination. While most schools in Ireland can be categorised as falling under the umbrella as either a primary or post-primary school, they can also be classified on other aspects relating to socio-economic status. As such, the DEIS (Delivering Equality of Opportunity in Schools) title is given to either primary or post-primary schools receiving a certain amount of support from the government because of the concentration of students coming from lower socio-economic backgrounds.

Regardless of school type, bullying is a significant problem in Irish schools, as it is elsewhere (Foody, Samara, El Asam, Morsi, \& Khattab, 2017a). In the traditional sense, it involves, negative and repeated behaviour towards someone who cannot easily defend themselves (Olweus, 1997). As such, there is always a power imbalance, with those who engage in the bullying behaviour generally holding a hierarchical stance. The definition of cyberbullying also includes aspects of repetitiveness, negative impact and power imbalance, although the methods of achieving these are fundamentally different to traditional bullying (e.g. sharing photos online, versus socially excluding someone from a game in the playground; Smith et al., 2008). Despite the differences, the two are undoubtedly interlinked and in many cases an online bullying incident is the result of actions offline and vice versus (Hemphill \& Heerde, 2014). As such, effectively dealing with traditional bullying could reduce risky and problematic behaviour online and more importantly, could decrease the negative effects on individuals involved.

A recent meta-analysis of all bullying studies on the island of Ireland found that $22.4 \%$ of students in primary schools and $11.8 \%$ in post-primary where victims of bullying (Foody, Samara, \& O'Higgins Norman, 2017b). Research demonstrating the specific impact of bullying on Irish pupils is relatively limited compared to other 
European countries such as the UK, which have several longitudinal studies (e.g. Wolke et al., 2012). However, specific Irish studies have linked bullying involvement to poorer self-esteem (O'Moore \& Kirkham, 2001), lower life satisfaction (Callaghan, Kelly, \& Molcho, 2015) and increased anxiety and depression (McMahon, Reulbach, Keeley, Perry, \& Arensman, 2010).

\section{The role of principals in Ireland}

The school unit is seen as an important conduit to student learning by providing a safe and secure environment for all students (Langford et al., 2015). Effective school leadership has been linked to student achievement and teacher job satisfaction; both of which are connected to school climate (Sebastian \& Allensworth, 2012; Rhodes, Camic, Milburn, \& Lowe, 2009). School climate also influences the social relationships within the school (Mainhard, Brekelmans, \& Wubbels, 2011) and interpersonal relationships and conflict resolution are increasingly important issues for principals to deal with (Morgan \& Sugrue, 2008; Stevens, 2013).

In Ireland, the school unit plays a wide role in the broader community and new responsibilities for principals are continuously emerging as they are required to respond to the increasingly diverse needs of students and parents (Darmody \& Smyth, 2016). This coupled with the ever-changing nature of funding allocations and government agendas, can make the principal's role a tight rope between policy and student experience. It has been suggested that current school leaders in Ireland feel increased pressure compared to previous generations (O'Donovan, 2015) and are at risk of developing mental health issues such as stress, anxiety and depression (Stevens, 2013).

Despite heavy responsibilities and the potential for stress, principals are internationally and locally recognised as agents of change as they possess the vision and skills necessary for both leadership and sustainable change. The role of the principal is imperative in creating a school climate that nurtures differences and equality at the same time. Indeed, effective practice is recognised as a product of strong leadership, which supports school culture and climates that celebrate differences (Ofsted, 2012). Furthermore, research shows that teacher perception of principal support directly impacts teacher self-efficacy for dealing with those who bully (Skinner, Babinski, \& Gifford, 2014). As such, there can be serious consequences for students if this is not the case and where principals fail to set appropriate examples of an inclusive and diverse learning environment.

O'Higgins Norman (2008) found that lack of proactive action against homophobic bullying in Irish post-primary schools was linked to a deficiency in leadership from school principals and boards of management. In addition, we know from research on teachers that opinions about bullying may be directly related to efforts to stop or reduce bullying (Kochenderfer-Ladd \& Pelletier, 2008) and that teacher efforts to intervene in bullying is related to school climate (Yoon, Sulkowski, \& 
Bauman, 2016). It has been argued that the individual principal's skills and attitude are central to setting the standard for other members of staff tackling bullying successfully. In turn, this may depend on the type of leadership model each individual adopts in their practice. As Day, Harris, and Hadfield (2001) concluded from their research, 'effective leadership is defined and driven by individual value systems' ( $p$. 32). If a school principal does not recognise bullying as an issue worth addressing, then his/her values can impact on the extent to which a school is ready to prevent and address bullying. Brennan and Mac Ruairc (2011) argue that demonstrating social awareness about what feelings to show in what circumstances is an essential leadership skill for a school principal. As such, leadership is a critical element to effectively dealing with bullying incidents (Meyer, 2008) and the skills and expertise of a principal play an essential role in effectively dealing with bullying incidents (Farrelly, O'Higgins Norman, \& O'Leary, 2016).

\section{Anti-bullying policy and procedures in Ireland}

In Ireland, the Equal Status Acts (2000-2015) outlines the standard duty of care that schools have in effectively dealing with any incident of harassment and/or bullying that occurs with staff or students. In addition, under the Education (Welfare) Act (2000), all Irish schools are required to have a code of behaviour in place which sets out the programmes, practices and procedures that together form the school's plan for helping students in the school to behave well and learn well (Section 23). A more specific mandate to tackle bullying was provided in 2013 when the Department of Education and Skills (DES) published the Anti-Bullying Procedures for Primary and Post-Primary Schools (2013). These arose out of a review of the 1993 Guidelines on Countering Bullying in Schools, a forum hosted by the Minister for Education and Skills with the Minister for Children and Youth Affairs (2012) and the Action Plan on Bulling-Report of the Anti-Bullying Working Group to the Minister for Education and Skills (January 2013). As such, the procedures represent the most significant development in relation to tackling bullying in schools in Ireland in 20 years. The purpose of these procedures is to give direction to school personnel in preventing and intervening with school-based bullying and in dealing with any negative impact that this may have on students. They provide a framework for principals and boards of management to work to and include suggestions for best practice. These include: taking appropriate preventative steps such as providing a policy, nominating a specific member of staff to deal with bullying and including formal reporting of bullying. The procedures also recognise best practice for effectively dealing with bullying and take note of certain relevant principles including: positive school climate; implementing education and prevention strategies (including raising awareness around the issue); and consistent recoding and follow-up of bullying behaviour. In addition, they consider the implementation of education and prevention strategies that build empathy, respect and resilience in students, to be best practice in tackling bullying behaviour. Clearly, as so much 
of the procedures related to the internal life of a school, the role of the principal and his/her leadership style is extremely relevant when considering the extent to which the national procedures are implemented at a local level.

Despite the considerable momentum the procedures created in 2013 in terms of advocacy for reducing bullying in our schools, bullying is still an issue for principals, especially with new concerns over cyberbullying and the impact this is having on our young people (Corcoran \& McGuckin, 2014; Foody, Samara, \& Carlbring, 2015; Ging \& O'Higgins, 2016; O'Moore, 2014). To date, there has been no investigation to see if principals are implementing the procedures and if there have been any challenges in doing so. There has been no follow-up by Irish Government to the National Action Plan, although there was a reference in the new government's recent Action Plan for Education (2017) which merely promised to review the implementation of the Plan. In addition, there is surprisingly little evidence investigating the attitudes of school principals on this approach or on bullying in general. For the most part investigations are concerned with student, teacher and parent experiences and relatively little examinations have placed the principals at the centre of their research questions.

This research was undertaken with these points in mind and with a view to understanding the contemporary issues facing Irish principals on the issue of bullying. Three main research objectives are central to the current study. First, we investigated principals' reporting of bullying incidents in their school and the impact this can have on their students. Second, we were curious as to the preventative measures and supports that principals are implementing for those involved in bullying, and if indeed, they were following best practice guidelines in this regard. Finally, we were concerned with the resources that principals felt they needed to increase their efforts in tackling bullying in their schools.

\section{Method}

\section{Participants}

An email database for all principals in the Republic of Ireland was obtained from the Department of Education and Skills. An email was sent to all school principals ( $N=4028$ ) in October 2016 asking them to participate in the study by completing an online survey. Email reminders were sent four subsequent times to principals with a request to complete the survey. The survey was closed in December 2016 with a final sample number of 918 principals, representing $23 \%$ of all schools across the Republic of Ireland.

\section{Questionnaire}

The survey was designed by the current authors with further input from the Central Policy Unit of the Department of Education \& Skills, the National Association for 
Principals and Deputy Principals (NAPD) and the Irish Primary Principals Network (IPPN). The survey instrument contained four general areas of interest:

(a) Demographic details (e.g. How many pupils/students attend your schools?)

(b) Frequency of bullying incidents (e.g. The number of bullying incidents reported in the past year have been?) and impact (e.g. Bullying behaviour can result in poor academic performance?)

(c) Supports in place for dealing with bullying (e.g. My school provides specific supports to those who have been bullied?)

(d) Preventative measures (e.g. My school has an anti-bullying policy).

Each section included quantitative questions with multiple choice answer options (e.g. strongly agree, agree, somewhat agree, strongly disagree, disagree, somewhat disagree be and don't know).

The following definition of bullying was provided to all participants: Bullying is defined by the Anti-Bullying Policy and Procedures for Primary and Post-Primary Schools (2013) published by the Department of Education \& Skills as 'unwanted negative behaviour, verbal, psychological or physical, conducted by an individual or group against another person or persons and which is repeated over time.' The following types of bullying behaviour are included in this non-exhaustive definition:

(I) deliberate exclusion, malicious gossip and other forms of relational bullying

(II) cyberbullying

(III) identity-based bullying such as homophobic bullying, racist bullying, bullying based on a person's membership of the Traveller community and bullying of those with disabilities or special educational needs.

\section{Results}

Data were analysed using the statistical software package SPSS. Respondents were categorised into four types of schools: mainstream primary schools (55.8\%), mainstream post-primary schools (21.8\%), DEIS (Delivering Equality of Opportunity in Schools) primary schools (16.9\%) and DEIS post-primary schools (5.5\%). The entire sample contained schools ranging in size from 1-179 pupils to over 1000 pupils and could also be categorised into boys' single sex, girls' single sex and co-educational in terms of gender (see Table 1).

\section{Bullying frequency and impact}

Overall, the most common number of incidents reported per term was up to 9 (78.9\% of sample), while the next common answer was 'Never' (13.2\%). Very few principals (17 of the entire sample) reported more than 20 bullying incidents in their school across term (see Table 2). Respondents were not required to answer 
Table 1. Descriptives for entire sample.

\begin{tabular}{lcc}
\hline & No/total no & \% of sample who answered \\
\hline School type & & \\
Boys & $82 / 909$ & 9.1 \\
Girls & $81 / 909$ & 8.9 \\
Mixed & $745 / 909$ & 82 \\
Size & & \\
$1-179$ pupils & $350 / 911$ & 38.5 \\
$179-400$ & $286 / 911$ & 31.4 \\
$401-700$ & $195 / 911$ & 21.4 \\
$700-1000$ & $61 / 911$ & 6.7 \\
$>1000$ & $18 / 911$ & 2 \\
Category & & \\
Primary & $507 / 909$ & 55.8 \\
DEIS Primary & $154 / 909$ & 16.9 \\
Post-primary & $198 / 909$ & 21.8 \\
DEIS Post-primary & $50 / 909$ & 5.5 \\
\hline
\end{tabular}

Table 2. Frequency of bullying incidents for each school category per school term.

\begin{tabular}{lcccc}
\hline & Never & $0-9$ & $10-19$ & $>20$ \\
\hline Primary (N=463) & & & & \\
No/total no & 65 & 370 & 22 & 6 \\
\% of sample who answered & 14 & 79.9 & 4.8 & 1.3 \\
$\begin{array}{l}\text { DEIS primary }(N=135) \\
\text { No/total no }\end{array}$ & 13 & 112 & 6 & 4 \\
\% of sample who answered & 9.6 & 83 & 4.4 & 3 \\
$\begin{array}{l}\text { Post-primary ( } N=179) \\
\text { No/total no }\end{array}$ & 24 & 134 & 15 & 6 \\
\% of sample who answered & 13.4 & 74.8 & 8.4 & 3.4 \\
$\begin{array}{l}\text { DEIS Post-primary }(N=47) \\
\text { No/total no }\end{array}$ & 5 & 35 & 6 & 1 \\
\% of sample who answered & 10.6 & 74.5 & 12.8 & 2.1 \\
Entire sample ( $N=833)$ & & & & \\
No/total no & 110 & 657 & 49 & 17 \\
\% of sample who answered & 13.2 & 78.9 & 5.9 & 2 \\
\hline
\end{tabular}

every question and so missing values means the samples do not add to one overall percentage.

When asked about the impact of bullying experiences on their students, the majority of principals agreed that bullying can lead to poor school attendance (87.3\% of overall sample) and poorer academic performance ( $97.5 \%$ of overall sample). This did not differ significantly between the different school categories.

\section{Preventative measures}

Nearly the entire sample reported having an anti-bullying policy present in their school (99.8\%) and 99\% agreed with the question 'staff in my school are clear on what steps to take to tackle bullying behaviour'. When asked about the reporting mechanisms for bullying incidents, $98.4 \%$ agreed with the question 'my school 
has procedures for the formal noting and reporting of bullying'. Reponses were more divided when the principals were asked if a specific member of staff had been appointed to investigate and tackle bullying in my school (50.6\% agree, 47\% disagree and 2.3\% don't know). Chi-square analysis showed that school type did not significantly affect responses to these questions $(p>.05)$.

\section{Supports for dealing with bullying}

Five questions were specifically related to the supports students received around bullying. Answers for the overall school sample and per school type are provided in Table 3. Overall, the majority of principals agreed that victims of bullying (82\%) and those who engage in bullying (74\%) could access specific supports in their school. Nearly all principals (93\%) also agreed with the question 'My school provides

Table 3. Opinion on supports split by school type.

\begin{tabular}{|c|c|c|}
\hline & Agree (\%) & Disagree (\%) \\
\hline \multicolumn{3}{|c|}{ Q1. My school provides specific supports to help those who are bullied } \\
\hline Primary & 81 & 19 \\
\hline DEIS Primary & 85 & 15 \\
\hline Post-primary & 80.2 & 19.8 \\
\hline DEIS Post-primary & 84.4 & 15.6 \\
\hline Overall Sample & 81.7 & 18.3 \\
\hline \multicolumn{3}{|c|}{ Q2. My school provides specific supports to help those who have bullied others } \\
\hline Primary & 63.7 & 26.3 \\
\hline DEIS Primary & 75.2 & 24.8 \\
\hline Post-primary & 72.6 & 27.4 \\
\hline DEIS Post-primary & 81.4 & 18.6 \\
\hline Overall Sample & 74.1 & 25.9 \\
\hline \multicolumn{3}{|c|}{ Q3. Our school has researched and identified a specific anti-bullying programme to use when dealing with bullying } \\
\hline Primary & 44.5 & 55.5 \\
\hline DEIS Primary & 47.5 & 52.5 \\
\hline Post-primary & 46.1 & 53.9 \\
\hline DEIS Post-primary & 34.1 & 65.9 \\
\hline Overall Sample & 44.9 & 55.1 \\
\hline \multicolumn{3}{|c|}{$\begin{array}{l}\text { Q4. Pupils/students in my school can easily access qualified counsellors when they experience bullying and other } \\
\text { emotional issues }\end{array}$} \\
\hline Primary & 35.2 & 64.8 \\
\hline DEIS Primary & 36.6 & 63.4 \\
\hline Post-primary & 54.9 & 45.1 \\
\hline DEIS Post-primary & 48.8 & 51.2 \\
\hline Overall Sample & 40.3 & 59.7 \\
\hline \multicolumn{3}{|c|}{ Q5. A specific member of staff has been appointed to investigate and tackle bullying in my school } \\
\hline Primary & 41.5 & 48.5 \\
\hline DEIS Primary & 51.6 & 48.4 \\
\hline Post-primary & 52 & 48 \\
\hline DEIS Post-primary & 55.6 & 44.4 \\
\hline Overall Sample & 50 & 50 \\
\hline \multicolumn{3}{|c|}{ Q6. My school provides sufficient time for social and emotional education (such as SPHE) } \\
\hline Primary & 92.5 & 7.5 \\
\hline DEIS Primary & 95.3 & 4.7 \\
\hline Post-primary & 91.2 & 8.8 \\
\hline DEIS Post-primary & 93.3 & 6.7 \\
\hline Overall Sample & 92.8 & 7.2 \\
\hline
\end{tabular}


sufficient time for social and emotional education (such as SPHE)'. Approximately half of the overall sample had researched and identified a specific anti-bullying programme (45\%) and/or appointed a specific member of staff to investigate and tackle bullying (50\%). Finally, only $40 \%$ of principals agreed that pupils in their school could access qualified counsellors when they experienced bullying.

A chi-square test for independence indicated no significant difference between the school groups on these questions 1, 2, 3, 5 and 6 (all ps > .05). There was, however, a significant difference for question 4 as mainstream post-primary schools agreed that their students could access counsellors more than the other school categories $\left[X^{2}(3, n=740)=20.843 ; p=.000 ;\right.$ phi $\left.=.168\right]$.

\section{Discussion}

The results presented document the issues and challenges facing Irish principals in dealing with bullying. Our questionnaire was developed within a uniquely Irish context where we could analyse differences between primary and post-primary schools and those with the DEIS status. In general, there appeared to be little differences between school type, a finding which may point to the homogenous nature of the Irish education system where principals appear to have similar needs despite school size, school gender or socio-economic status. However, there were some differences and other noteworthy findings which we will discuss here.

Most schools reported up to 9 incidents of school bullying per term and only $2 \%$ of the entire sample reported more than 20 incidents for the same timeframe. The general procedure for dealing with bullying within a school system is for the teacher to be the first point of contact when making a complaint. We know from the literature that teachers often respond ineffectively to such incidents (Yoon et al., 2016) and report the need for additional training on how to deal with bullying effectively (Bradshaw, Waasdorp, O'Brennan, \& Gulemetova, 2011). In addition, the current research shows that less than half the sample have a designated person to deal with bullying in their school. As such, it is possible that principals are unaware of the extent of bullying and therefore may have under-reported bullying incidents. This seems especially viable when we know that the average rate of bullying (either traditional or cyber) in Ireland is between 12 and 23\% (Foody et al., 2017b). One could deduce that the incident rate should be higher if at least one in five students is experiencing bullying at some stage in their schooling. Indeed, there are examples in the literature which found discrepancies between principal and student reports of bullying and noted a general trend of principals to under-report (Fröjd, Saaristo, \& Ståhl, 2013).

The high number (99.8\%) of principals reporting the presence of an anti-bullying policy is not surprising considering this is a legal requirement of all schools. Nevertheless, it does document some increase in recent years as Corcoran and McGuckin (2014) found only 73\% of Irish principals implemented such a policy. Although the current results are positive, further research is needed to investigate 
the nature and type of these policies and if indeed they are detailed enough. For example, Farrelly et al. (2016) found that only half of their sample of Irish principals had experience of dealing with cases of homophobic bullying and one could question the extent to which their policies reflected this. A recent content analysis of anti-bullying policies in schools in Northern Ireland found minimal allowances for racist, religious, homophobic or sexual bullying, despite good coverage of traditional and cyberbullying (Purdy \& Smith, 2016). As such we urge caution on considering the current finding as positive and call for further research to first investigate the content of such policies in schools in the Republic of Ireland.

Nearly all principals were aware of the negative impact of bullying on attendance and academic performance at school. This finding, together with the reported gaps in access to qualified counsellors, raises concern about the welfare of students who are involved in bullying in our schools. A lack of access to counsellors and psychological support risks a situation where problems associated with mental or emotional health become worse without early intervention. In addition, when a school does not have access to such resources, responsibility for dealing with mental health issues often falls to teachers. This is not an effective anti-bullying strategy as school staff are rarely appropriately skilled to deal with serious psychological issues and there is often no follow-up for those involved in terms of their mental health and/or their coping strategies. In addition, there is evidence that teachers and counsellors respond differently to bullying reports which could be as a result of differences in training backgrounds (Bauman, Rigby, \& Hoppa, 2008). For example, Jacobson and Bauman (2007) reported increased empathy for school counsellors compared to teachers when presented with bullying cases.

Interestingly, post-primary schools reported increased access to counsellors compared to the other schools. This finding represents the fact that guidance counsellors and chaplains are often recruited for post-primary schools and considered a standard post, especially in larger schools. While widely accepted, it does seem unbalanced that the same support would not be provided for primary schools, especially when we know that bullying is generally higher in this age group (Foody et al., 2017b). On a similar note, only half of the current principals agreed that they had appointed a specific member of staff to investigate and tackle bullying in their school. This is concerning as it is specifically stated in the principals that a 'school's anti-bullying policy must clearly indicate the relevant teachers in its school'. It is not necessary to specify the relevant teacher(s) by name in the policy so long as it is made sufficiently clear to all which teacher(s) have this responsibility. This again, raises the issue of content of anti-bullying policies and if indeed they contain the necessary information, despite being present in the majority of schools. We would also argue that identifying one or more appointed teachers is an important anti-bullying strategy in any school as it provides students with some comfort that they know their first point of contact if they are involved with bullying.

It is also worrying that less than half of the principals in the current study had researched and identified a specific anti-bullying programme to use when dealing 
with bullying in their schools. Indeed, this was an area principals felt more direction and guidance was needed from the Department of Education and Skills. This finding replicates previous research by Corcoran and McGuckin (2014) who also reported that Irish principals wanted more training for staff, resources, workshops and guidelines, particularly in relation to social networking sites and online behaviour of their students. This issue appears to be just as prevalent in current times and one area that has not changed since the introduction of the procedures. Given that most teachers will come across a bullying incident at some point in their career and the fact that anti-bullying training is not mandatory in teacher training courses in Ireland (Teaching Council of Ireland, 2017); it is imperative that they receive such training (Bauman et al., 2008). Teacher and principal responses are critical to reducing bullying and to increasing proactive behaviour by bystanders (Hektner \& Swenson, 2012; Yoon \& Bauman, 2014).

School-wide programmes often include both policy and awareness with a view to changing attitudes and behaviours in all parties involved (i.e. teachers, students, practitioners and parents). The importance of anti-bullying programmes have been highlighted elsewhere (e.g. Bauman et al., 2008) and the current results clearly document the need and want from principals in Ireland for resources to implement such an intervention. Such a programme would be informed by findings from national and international research which demonstrated the need to take a wholeschool approach led by a specific staff member or a school committee (Downes \& Cefai, 2016; O'Higgins Norman \& Sullivan, 2018). We know from international research that schools with anti-bullying programmes respond better to bullying incidents and staff are less likely to ignore reports of bullying (Bauman et al., 2008; Ttofi \& Farrington, 2011). Indeed, the national implementation of such an intervention may mark a move to a more preventative approach to tackling the issue.

This research has provided insight into contemporary issues facing principals dealing with bullying in Irish schools. While it has highlighted the biggest areas of concern, namely lack of access to counsellors and no guidance on an anti-bullying prevention strategy; it has also demonstrated the positive actions our principals are taking. The current research showed that the majority of Irish principals provided specific supports for both bullies and victims and felt that their school provided sufficient time for social and emotional education such as SPHE. There is, however, one limitation to this research that needs to be considered. Because of the self-selection process by which respondents completed this questionnaire, we need to consider that the sample is not entirely representative of all principals in Ireland. One could argue that the respondents willing to take part in this study were those already taking affirmative action against bullying in their school. Indeed, if this were the case, it highlights further the need for increased access to counsellors and a specific anti-bullying programme as these principals who are clearly taking some proactive steps (e.g. anti-bullying policies) are still struggling in both these areas.

The Action Plan on Bullying (2013) and related Procedures for Primary and PostPrimary Schools has provided a national integrated strategic approach to tackling 
bullying in schools. This research highlights some areas of progress in recent years, potentially as a result of such guidelines. Increased presence of anti-bullying policies and the provision of supports for those who engage in bullying and those who experience bullying were overwhelming demonstrated in this research. On this note, it appears that the procedures have created some tangible change and positive actions since their introduction in 2013. However, based on responses from principals it seems that many of them have not been able to meet the procedure's requirement to provide access to counsellors when needed and/or identify the most suitable intervention for their school.

\section{Disclosure statement}

No potential conflict of interest was reported by the authors.

\section{Funding}

The project was funded by the DCU Institute of Education Shared Research Fund. The first author is funded by the Irish Research Council Government of Ireland Postdoctoral Fellowship.

\section{References}

Anti-Bullying Working Group. (2013). Action plan on bullying report of the anti-bullying working group to the minister for education and skills. Dublin: Department of Education and Skills.

Bauman, S., Rigby, K., \& Hoppa, K. (2008). US teachers' and school counsellors' strategies for handling school bullying incidents. Educational Psychology, 28(7), 837-856. doi:10.1080/01443410802379085

Bradshaw, C. P., Waasdorp, T. E., O'Brennan, L. M., \& Gulemetova, M. (2011). Findings from the national education association's nationwide study of bullying: Teachers' and education support professionals' perspectives. Washington, DC: National Education Association.

Brennan, J., \& Mac Ruairc, G. (2011). Taking it personally: Examining patterns of emotional practice in leading primary schools in the Republic of Ireland. International Journal of Leadership in Education, 14, 129-150.

Callaghan, M., Kelly, C., \& Molcho, M. (2015). Exploring traditional and cyberbullying among Irish adolescents. International Journal of Public Health, 60(2), 199-206. doi:10.1007/s00038014-0638-7

Corcoran, L., \& McGuckin, C. (2014). Addressing bullying problems in Irish schools and in cyberspace: A challenge for school management. Educational Research, 56(1), 48-64. doi:10 $.1080 / 00131881.2013 .874150$

Darmody, M., \& Smyth, E. (2016). Primary school principals' job satisfaction and occupational stress. International Journal of Educational Management, 30(1), 115-128.

Day, C., Harris, A., \& Hadfield, M. (2001). Grounding knowledge of schools in stakeholder realities: A multi-perspective study of effective school leaders. School Leadership \& Management, 21, $19-42$.

Department of Education and Skills. (2013). Anti-bullying procedures for primary and post primary schools. Dublin: Author. 
Department of Education and Skills. (2017). Action Plan for Education. Dublin: Author. Retrieved from https://www.education.ie/en/Publications/Corporate-Reports/Strategy-Statement/ Action-Plan-for-Education-2017.pdf

Downes, P., \& Cefai, C. (2016). How to prevent and tackle bullying and school violence: Evidence and practices for strategies for inclusive and safe schools. Luxembourg: Publication Office of the European Union.

Farrelly, G., O'Higgins Norman, J., \& O'Leary, M. (2016). Custodians of silences? School principal perspectives on the incidence and nature of homophobic bullying in primary schools in Ireland. Irish Educational Studies, 1-17. doi:10.1080/03323315.2016.1246258

Foody, M., Samara, M., \& Carlbring, P. (2015). A review of cyberbullying and suggestions for online psychological therapy. Internet Interventions, 2(3), 235-242.

Foody, M., Samara, M., El Asam, A., Morsi, H., \& Khattab, A. (2017a). A review of cyberbullying legislation in Qatar: Considerations for policy makers and educators. International Journal of Law and Psychiatry, 50, 45-51.

Foody, M., Samara, M., \& O'Higgins Norman, J. (2017b). Bullying and cyberbullying studies in the school-aged population on the island of Ireland: A meta-analysis. British Journal of Educational Psychology, 87(4), 535-557. doi:10.1111/bjep.12163

Fröjd, S., Saaristo, V., \& Ståhl, T. (2013). Monitoring bullying behaviours may not enhance principal's awareness of the prevalence. School Leadership \& Management, 34(5), 470-480. doi:10.1080/13632434.2013.849683

Ging, D., \& O'Higgins, Norman J. (2016). Cyberbullying, conflict management or just messing? Teenage girls' understandings and experiences of gender, friendship, and conflict on Facebook in an Irish second-level school. Feminist Media Studies, 16(5), 805-821.

Hektner, J. M., \& Swenson, C. A. (2012). Links from teacher beliefs to peer victimization and bystander intervention: Tests of mediating processes. Journal of Early Adolescence, 32, 516536. doi:10.1177/0272431611402502

Hemphill, S. A., \& Heerde, J. A. (2014). Adolescent predictors of young adult cyberbullying perpetration and victimization among australian youth. Journal of Adolescent Health, 55(4), 580-587.

Jacobson, K., \& Bauman, S. (2007). School counsellors' responses to school bullying scenarios. Professional School Counselling, 11, 1-9.

Kasen, S., Berenson, K., Cohen, P., \& Johnson, J. G. (2004). The effects of school climate on changes in aggressive behavior and other behaviors related to bullying. In D. L. Espelage \& S. M. Swearer (Eds.), Bullying in American schools: A social-ecological perspective on prevention and intervention (pp. 187-210). Mahwah, NJ: Erlbaum.

Kochenderfer-Ladd, B., \& Pelletier, M. E. (2008). Teachers' views and beliefs about bullying: Influences on classroom management strategies and students' coping with peer victimization. Journal of School Psychology, 46(4), 431-453. doi:10.1016/j.jsp.2007.07.005

Langford, R., Bonell, C., Jones, H., Pouliou, T., Murphy, S., Waters, E., ... Campbell, R. (2015). The World Health Organization's health promoting schools framework: A Cochrane systematic review and meta-analysis. MBC Public Health, 15, 130.

Mainhard, M. T., Brekelmans, M., \& Wubbels, T. (2011). Coercive and supportive teacher behaviour: Within- and across-lesson associations with the classroom social climate. Learning and Instruction, 21(3), 345-354.

McMahon, E. M., Reulbach, U., Keeley, H., Perry, I. J., \& Arensman, E. (2010). Bullying victimisation, self harm and associated factors in Irish adolescent boys. Social Science \& Medicine, 71(7), 1300-1307. doi:10.1016/j.socscimed.2010.06.034

Meyer, E. J. (2008). Gendered harassment in secondary schools: Understanding teachers' (non) interventions. Gender and Education, 20(6), 555-570. doi:10.1080/09540250802213115 
Morgan, M., \& Sugrue, C. (2008). The seven challenges and four rewards of being a school principal: Results of a national survey. Oideas, 52, 8-26.

O'Donovan, M. (2015). The challenges of distributing leadership in Irish post-primary schools. International Electronic Journal of Elementary Education, 8(2), 243-266.

O’Higgins Norman, J. (2008). Homophobic bullying in Irish secondary education. Dublin: Academica Press.

O'Higgins Norman, J., \& Sullivan, K. (2018). Reducing school bullying: A whole-school approach. In H. Cowie \& C. A. Myers (Eds.), Bullying in schools: Intervention and prevention (pp. 180-191). Oxfordshire: Routledge.

O'Moore, A. (2014). Understanding cyberbullying: A guide for parents and teachers. Dublin: Veritas.

O'Moore, A., Kirkham, C., \& Smith, M. (1997). Bullying behaviour in Irish schools: A nationwide study. The Irish Journal of Psychology, 18(2), 141-169. doi:10.1080/03033910.1997.10558137

O'Moore, M., \& Kirkham, C. (2001). Self-esteem and its relationship to bullying behaviour. Aggressive Behaviour, 27(4), 269-283. doi:10.1002/ab.1010

Ofsted. (2012). The annual report of her majesty's chief inspector of education, children's services and skills 2011/12. London: The Stationery Office. Retrieved from http://www.official-document. gov.uk/

Olweus, D. (1997). Bullying/victim problems in school: Facts and intervention. European Journal of Psychology of Education, 12(4), 495-510.

Purdy, N., \& Smith, P. K. (2016). A content analysis of school anti-bullying policies in Northern Ireland. Educational Psychology in Practice, 32(3), 281-295. doi:10.1080/02667363.2016.116 1599

Rhodes, J. E., Camic, P. M., Milburn, M., \& Lowe, S. R. (2009). Improving middle school climate through teacher-centered change. Journal of Community Psychology, 37, 711-724. doi:10.1002/ Jcop.20326

Rivers, I., Poteat, V. P., Noret, M., Ashurst, N., \& Kamphaus, R. W. (2009). Observing bullying at school: The mental health implications of witness status. School Psychology Quarterly, 24(4), 211-223.

Sebastian, J., \& Allensworth, E. (2012). The influence of principal leadership on classroom instruction and student learning: A study of mediated pathways to learning. Educational Administration Quarterly, 48(4), 626-663.

Skinner, A. T., Babinski, L. M., \& Gifford, E. J. (2014). Teachers' expectations and self-efficacy for working with bullies and victims. Psychology in the Schools, 51(1), 72-84.

Smith, P. K., Mahdavi, J., Carvalho, M., Fisher, S., Russell, S., \& Tippett, N. (2008). Cyberbullying: Its nature and impact in secondary school pupils. Journal of Child Psychology and Psychiatry, 49(4), 376-385.

Srabstein, J. C., \& Leventhal, B. L. (2010). Prevention of bullying-related morbidity and mortality: A call for public health policies. Bulletin of the World Health Organization, 88, 403.

Stevens, P. (2013). The Bullying of primary school principals in Ireland. In M. O'Moore \& P. Stevens (Eds.), Bullying in Irish education: Perspectives in research and practice (pp. 40-65). Cork: Cork University Press.

Teaching Council of Ireland. (2017). Initial Teacher Education Criteria and Guidelines for Providers. Maynooth: Teaching Council.

Ttofi, M. M., \& Farrington, D. P. (2011). Effectiveness of school-based programs to reduce bullying: A systematic and meta-analytic review. Journal of Experimental Criminology, 7(1), 27-56.

Ttofi, M. M., Farrington, D. P., \& Lösel, F. (2012). School bullying as a predictor of violence later in life: A systematic review and meta-analysis of prospective longitudinal studies. Aggression and Violent Behavior, 17(5), 405-418. 
United Nations Special Representative of the Secretary-general on Violence Against Children. (2013). Ending the torment: Tackling bullying from schoolyard to cyberspace. New York, NY: Author.

Wolke, D., Schreier, A., Zanarini, M., \& Winsper, C. (2012). Bullied by peers in childhood and borderline personality symptoms at 11 years of age: A prospective study. Journal of Child Psychology and Psychiatry, 53(8), 846-855.

Wolke, D., Copeland, W. E., Angold, A., \& Costello, E. J. (2013). Impact of bullying in childhood on adult health, wealth, crime, and social outcomes. Psychological Science, 24(10), 1958-1970.

Yoon, J., \& Bauman, S. (2014). Teachers: A critical but overlooked component of bullying prevention and intervention. Theory Into Practice, 53, 308-314. doi:10.1080/00405841.201 4.947226

Yoon, J., Sulkowski, M. L., \& Bauman, S. A. (2016). Teachers' responses to bullying incidents: Effects of teacher characteristics and contexts. Journal of School Violence, 15(1), 91-113. doi:10.108 0/15388220.2014.963592 